\title{
AN EVALUATION FOR SUSTAINABLE MOBILITY EXTENDED BY D NUMBERS
}

\author{
Hongming $\mathrm{MO}^{1,2}$, Yong $\mathrm{DENG}^{1^{*}}$ \\ ${ }^{1}$ Institute of Fundamental and Frontier Science, University of Electronic Science \\ and Technology of China, Chengdu, Sichuan, 610054, China \\ ${ }^{2}$ Library, Sichuan Minzu College, Kangding Sichuan 626001, China
}

Received 28 May 2018; accepted 10 February 2019

\begin{abstract}
How to evaluate the impact of transport measures on city sustainability effectively is still an open issue, and it can be abstracted as one of the multiple criteria decision making problems. In this paper, a new method based on $\mathrm{D}$ numbers is proposed to evaluate the sustainable mobility of city. D number is a new mathematical tool to represent and deal uncertain information. The property of integration of $\mathrm{D}$ numbers is employed to fusion information. A numerical example of carsharing demonstrates the effectiveness of the proposed method.
\end{abstract}

Keywords: belief function, D numbers, evidence theory, sustainability, decision making.

JEL Classification: D74, D81, L91, Q01, Q56, R41.

\section{Introduction}

The concept of sustainability was first put forward in the Brundtland Report of 1987 (Burton, 1987). Sustainable development can be detailed understood in many aspects, such as environmental sustainability (Kaklauskas et al., 2018), economic sustainability (Anand \& Sen, 2000), social sustainability (Dempsey, Bramley, Power, \& Brown, 2011), transportation sustainability (Banister, 2008), constructional sustainability (Lazauskas, Zavadskas, \& Šaparauskas, 2015), and so on. Sustainable mobility, as one of the good measures to the sustainable development of transportation (Cascetta, Carteni, Pagliara, \& Montanino, 2015; Naess, 2001), has become a hot issue recent years. Transport planning is very important for the sustainable development of urban (Cascetta, 2009; Cascetta \& Pagliara, 2013; Ortuzar \& Willumsen, 2011; Akyelken, Banister, \& Givoni, 2018; Carteni, 2017). With the rapid development of society, economy and environment, the current situations of traffic of the city are faced with congestion (Moya-Gómez \& García-Palomares, 2017), environmental pollution

${ }^{\star}$ Corresponding author. E-mails: dengentropy@uestc.edu.cn; prof.deng@hotmail.com 
(Amegah \& Agyei-Mensah, 2017), energy consumption (Rehermann \& Pablo-Romero, 2018) and time-consuming (Rai, Van Lier, Meers, \& Macharis, 2017).

Carsharing, as one of the popular measures to solve the problem of traffic, has attracted more and more attention from the views of researchers and city managers. Carsharing provides a new way to use a car rather than purchase a car. Carsharing is a new model of car rental where people rent cars for short periods of time, often by the hour (Katzev, 2003). There are many advantages in the model of carsharing, such as money-saving, improving vehicle utilization efficiency, convenience, environment friendly, reducing traffic jam, and so on, as detailed discussed later. Besides, there are still other measures of sustainable transportation recently (Litman \& Burwell, 2006). Carpooling is the sharing of car journeys so that more than one person travel in a car, and prevents the need for others to have to drive to a location themselves (Bachmann, Hanimann, Artho, \& Jonas, 2018; Domarchi, Coeymans, \& de Dios Ortúzar, 2018). Limiting car use, by constructing vehicle restricted zones, drawing peak-time lines for shifts, and setting traffic restrictions, is a way to reduce the number of cars on the road, which has been widely adopted by such Chinese cites as Beijing, Shanghai, Guangzhou and Chengdu (Nordlund \& Garvill, 2003). People are encouraged to cycle and walk in short-distance travel, which has some remarkable advantages, such as physical exercise, energy conservation and emission reduction (Ogilvie, Egan, Hamilton, \& Petticrew, 2004). The measure of optimizing the road network aims to minimize the total travel cost in the road network and improve the traffic efficiency of the road (Yang, Deng, \& Jones, 2018). The purpose of congestion pricing is to have less cars on the road and improve the traffic efficiency, but that is still a disputable measure for sustainable development in transportation (Cascetta, Carteni, \& Henke, 2017). Develop clean fuels, such as electricity, biodiesel or plug-in hybrid electric to replace the traditional gas fuel, avoiding energy dilemma (Steenberghen \& Lopez, 2008; Carteni, 2018). Design energy efficient vehicles using the new energy-saving technology such as stop-and-start engine (Wellmann, Govindswamy, \& Tomazic, 2013; Cordera, dell'Olio, Ibeas, \& Ortúzar, 2018). The implementation of these transportation measures are useful to contribute to urban sustainability from the views of environment, societal benefits and economy, more or less.

However before implementing a new mobility solution, an assessment is necessary to verify whether it will bring real benefits or not (Soria-Lara \& Banister, 2018; Cartenì, De Guglielmo, Pascale, \& Calabrese, 2017; Singh, Murty, Gupta, \& Dikshit, 2009). The Transport Canada Project Report by Wellar (Wellar, 2009) presented 42 methods which can be used to evaluate sustainability of urban transportation, such as life cycle analysis, cost-benefit analysis, environmental impact assessment, multi-criteria decision analysis, Delphi techniques, surveys, indexing, simulation model (Toledo \& Koutsopoulos, 2004), optimization method (Belenky, 2013), ecological footprinting method (Browne, O’Regan, \& Moles, 2008), and so on. The life cycle analysis is used to combine some criteria in the polluting emissions and resources during the life course of a product, which is originally used for industrial processes. Life cycle analysis has been widely used for evaluation environmental impact of transport system (Larson, 2006) and municipal solid waste management systems (Cleary, 2009). Cost-benefit analysis takes as many positive and negative impacts of a project as possible into consideration, which aims to minimize the necessary costs of the 
achievement of a given project and maximizing the benefits (Cartenì, De Guglielmo, \& Pascale, 2018; Kunreuther, Grossi, Seeber, \& Smyth, 2003; Venables, 2007). Cost-benefit analysis has been carried out for evaluation intelligent transportation systems (Thill, Rogova, \& Yan, 2004) and the Stockholm congestion charging system in Sweden (Eliasson, 2009). Besides the aforementioned methods, multi-criteria decision making (MCDM) method has also been involved to evaluate the sustainability, which provides a framework to make a definite result or an alternative using a set of criteria by a group decision makers. Affinity diagram and fuzzy technique for order preference by similarity to ideal solution (TOPSIS) were integrated for sustainable city logistics planning (Awasthi \& Chauhan, 2012). Decision-making trial and evaluation laboratory (DEMATEL) method (Han \& Deng, 2018a) has been used to improve sustainable supply chain management (Su et al., 2016). Analytic hierarchy process (AHP) and Vlsekriterijumska Optimizacija I KOmpromisno Resenje (VIKOR) methods (Fei, Deng, $\& \mathrm{Hu}, 2018$ ) have been integrated for the selection of sustainable manufacturing (Singh, Olugu, Musa, Mahat, \& Wong, 2016). Some other commonly used MCDM methods are multi-attribute utility function theory (MAUT) (Keeney, Raiffa, \& Rajala, 1979), outranking method (Opricovic \& Tzeng, 2007), evaluation ased on distance from average solution (EDAS) method (Keshavarz Ghorabaee, Zavadskas, Amiri, \& Turskis, 2016), weighted aggregated sum product assessment (WASPAS) method (Zavadskas, Kalibatas, \& Kalibatiene, 2016), and so on (Wei, Alsaadi, Hayat, \& Alsaedi, 2018; Hashemkhani Zolfani, Maknoon, \& Zavadskas, 2016; Zavadskas, Antuchevičienè, \& Chatterjee, 2019; Siksnelyte, Zavadskas, Streimikiene, \& Sharma, 2018; Siksnelyte, Zavadskas, Bausys, \& Streimikiene, 2019).

In the previous study, Dempster-Shafer (D-S) theory (Dempster, 2008; Shafer, 1976) has been used to evaluate sustainable transport measures (Awasthi \& Chauhan, 2011; Chen \& Deng, 2018a). In their study, D-S theory was adopted to do the processes of information fusion and decision making for its ability to deal with unknown and ignorance information. And D-S theory has been widely applied in many areas, such as engine fault diagnosis (Zhang \& Deng, 2018), risk assessment (Han \& Deng, 2018b)), target recognition (Han \& Deng, 2018c) and so on (Li \& Deng, 2018; Chen \& Deng, 2018b). However, there exist some strong restrictions when D-S theory is employed, such as elements in the set must be mutual exclusion and the basic probability assignments must be complete (Fei \& Deng, 2018; Yin, Deng, X. \& Deng, Y., 2019; Li, Zhang, \& Deng, 2018). Recently, a new mathematical tool to represent unreliable information, named D numbers (Deng, 2012), was proposed by Deng in 2012, which mirrors the framework of D-S theory. D numbers inherit all the advantage of $\mathrm{D}-\mathrm{S}$ theory. And the above mentioned restrictions of D-S theory are overcome in D numbers, as discussed later. D number provides a more flexible way to represent uncertain information, and it has been widely used in many areas, such as supplier selection (Deng, X. \& Deng, Y., 2018), risk assessment (Liu, You, Fan, \& Lin, 2014), linguistic decision making (Mo \& Deng, 2016), efficiency assessment (Fan, Zhong, Yan, \& Yue, 2016), health-care waste management (Xiao, 2018), radiation source identification (Guan, Liu, Yi, \& Zhao, 2018), etc (Mo \& Deng, 2018). Besides, D number has been together with other tools to solve other problems. Li and Chen (2018) utilized D numbers and intuitionistic hesitant fuzzy sets to solve the problem of multiple attribute decision making. Lin, Li, Xu, Liu, D., and Liu, J. (2018) based on D numbers and DEMATEL methods to identify and analysis the risks for new energy power 
system in China. Bian, Zheng, Yin and Deng (2018) improved the traditional failure mode and effects analysis (FMEA) method based on D numbers and TOPSIS.

Inspired by the application of $\mathrm{D}$ numbers, especially for its ability of information integration, a new method to assess sustainable mobility based on D numbers is proposed in this paper. In order to verify the effectiveness of the proposed method, a sustainable mobility application of carsharing is employed.

The remainder of the manuscript is organized as follows. The basic concepts of D-S theory and D numbers are recalled in Section 1. The detailed steps of the proposed method are given in Section 2. An application of carsharing to demonstrate the detailed processes of the proposed method and sensitivity analysis are presented in Section 3. A short conclusion is drawn in the last section.

\section{Preliminaries}

In this section, some basic concepts and properties of D-S theory and D numbers will be recalled.

\subsection{D-S theory}

D-S theory was first proposed by Dempster in 1967 (Dempster, 2008), and later extended by Shafer in 1976 (Shafer, 1976). It allows one to combine evidences from different sources and arrive at a degree of belief (represented by a belief function) that takes into account all the available evidences. D-S theory is similar to Bayesian probability theory, however there still exist some differences. The prior information is not necessary in D-S theory, whereas it is essential in Bayesian probability theory. And the information in D-S theory may be the form of singleton or subset, however it must be the form of singleton in Bayesian probability theory. In D-S theory, a problem domain is denoted by a finite nonempty set of mutually exclusive and exhaustive hypotheses, called the framework of discernment. Some basic concepts of D-S theory are introduced as follows.

Let $\Omega=\left\{\theta_{1}, \theta_{2}, \cdots, \theta_{n}\right\}$ be a finite set of $n$ elements. Let $2^{\Omega}$ denote the power set of $\Omega$, and $2^{\Omega}=\left\{\varnothing, \theta_{1}, \cdots, \theta_{n}, \theta_{1} \cup \theta_{2}, \theta_{1} \cup \theta_{3} \cdots, \Omega\right\}$.

Definition 1: For a framework of discernment $\Omega$, a basic probability assignment (BPA) function is a mapping $m: 2^{\Omega} \rightarrow[0,1]$, which is also called a mass function, satisfying

$$
m(\varnothing)=0 \text { and } \sum_{A \in 2^{\Omega}} m(A)=1,
$$

where $\varnothing$ is an empty set and $A$ is any element of $2^{\Omega}$. If $m(A)>0, A$ is called a focal element, the union of all focal elements is called the core of mass function. The mass function $m(A)$ represents how strongly the evidence supports A. Given two BPAs $m_{1}$ and $m_{2}$, Dempster's combination rule (Dempster, 2008) can be used to combine them and yield a new BPA.

Definition 2: Dempster's rule of combination, also called orthogonal sum, denoted as $m=m_{1} \oplus m_{2}$, is defined as

$$
m(A)=\frac{1}{1-k} \sum_{B \cap C=A} m_{1}(B) m_{2}(C)
$$


with

$$
k=\sum_{B \cap C=\varnothing} m_{1}(B) m_{2}(C)
$$

where $A, B$ and $C$ are the elements of $2^{\Omega}$, and $k$ is a normalization constant, called the conflict coefficient between two BPAs. The Dempster's rule of combination is the core of D-S theory, satisfying commutative and associative properties, i.e., (1) $m_{1} \oplus m_{2}=m_{2} \oplus m_{1}$ (2) $\left(m_{1} \oplus m_{2}\right) \oplus m_{3}=m_{1} \oplus\left(m_{2} \oplus m_{3}\right)$. Thus if there exist multiple BPAs, the combination of them can be carried out in a pairwise way with any order.

\subsection{D numbers}

D-S theory can be carried out under some specific situations of the set on the frame of discernment must be mutually exclusive and collectively exhaustive. However, in many reallife situations, the hypothesis cannot be always satisfied. For example, there are no crisp division among linguistic hypothesis set of "excellent", "well" and "bad". And the BPAs in D-S theory are assumed to be total independent and come from separated sources, which also limit its application. Besides, BPAs in D-S theory must be with completeness constraint, which is the sum of all mass functions in a BPA must be equal to 1. However, in many real-life situations, due to lack of abundant knowledge or subject to some constraints, it is possible to obtain partial information and generate incomplete BPAs. For example, in an open world (Smets \& Kennes, 1994), the incompleteness of framework of discernment may lead to incompleteness of representation. Additionally, the combination rule of Dempster is with highly computational complexity, which also limits its application. Recently, a new mathematical tool to represent uncertain information, named D numbers (Deng, 2012), is emerged under the framework of D-S theory, which absorbs the advantages of D-S theory, but overcomes the limitations of D-S theory. D number needs weaker restrictions than classical D-S theory, and it can be viewed as an extension of D-S theory. Some basic concepts of $\mathrm{D}$ numbers are shown as follows.

Definition 3: Let $\Omega$ be a finite nonempty set, a $D$ number is a mapping that $D: \rightarrow[0,1]$, with

$$
\sum_{A \subseteq \Omega} D(A) \leq 1 \text { and } D(\varnothing)=0 .
$$

Where $\varnothing$ is an empty set and $A$ is any subset of $\Omega$. It should be pointed out that different from D-S theory, the elements in set do not require mutually exclusive and the completeness constraint is not necessary in $\mathrm{D}$ numbers. If $\sum_{A \subseteq \Omega} D(A)=1$, the information is said to be complete; otherwise, the information is assumed to be incomplete. For a discrete set $\Omega=\left\{b_{1}, b_{2}, \cdots, b_{i}, b_{j}, \cdots b_{n}\right\}$, where $b_{i} \in R^{+}$, and $b_{i} \neq b_{j}$ when $i \neq j$, a special form of D numbers can be expressed by

$$
D\left(b_{1}\right)=v_{1}, D\left(b_{2}\right)=v_{2}, \cdots, D\left(b_{i}\right)=v_{i}, D\left(b_{j}\right)=v_{j}, \cdots, D\left(b_{n}\right)=v_{n}
$$

simply denoted as $D=\left\{\left(b_{1}, v_{1}\right),\left(b_{2}, v_{2}\right) \cdots\left(b_{i}, v_{i}\right),\left(b_{j}, v_{j}\right) \cdots\left(b_{n}, v_{n}\right)\right\}$, where $v_{i}>0$ and $\sum_{i=1}^{n} v_{i} \leq 1$.

Similar to D-S theory, there are also several properties of D numbers, given as follows. 
Property 1 (Permutation invariability): If there are two $\mathrm{D}$ numbers $D_{1}=$ $\left\{\left(b_{1}, v_{1}\right) \cdots\left(b_{i}, v_{i}\right) \cdots\left(b_{n}, v_{n}\right)\right\}$ and $D_{2}=\left\{\left(b_{n}, v_{n}\right) \cdots\left(b_{i}, v_{i}\right) \cdots\left(b_{1}, v_{1}\right)\right\}$, then $D_{1} \Leftrightarrow D_{2}$, where $\Leftrightarrow$ means "equal to".

Example 1: If there are two $D$ numbers: $D_{1}=\{(1,0.1),(3,0.2),(5,0.7)\}$ and $D_{2}=$ $\{(3,0.2),(1,0.1),(5,0.7)\}$, then $D_{1} \Leftrightarrow D_{2}$.

Example 2: If there are two D numbers: $D_{1}=\{(a, 0.4),(b, 0.35),(c, 0.25)\}$ and $D_{2}=$ $\{(b, 0.35),(a, 0.4),(c, 0.25)\}$, then $D_{1} \Leftrightarrow D_{2}$.

Property 2 (Integration): For a discrete D number, $D=\left\{\left(d_{1}, v_{1}\right), \cdots\left(d_{i}, v_{i}\right) \cdots\left(d_{n}, v_{n}\right)\right\}$, the integration operator of $\mathrm{D}$ numbers is defined as

where $d_{i} \in R^{+}, v_{i}>0$ and $\sum_{i=1}^{n} v_{i} \leq 1$.

$$
I(D)=\sum_{i=1}^{n} d_{i} v_{i}
$$

Example 3: Suppose a D number: $D=\{(1,0.2),(2,0.3),(3,0.1),(4,0.2),(5,0.2)\}$, then $I(D)=$ $1 \times 0.2+2 \times 0.3+3 \times 0.1+4 \times 0.2+5 \times 0.2=2.9$.

Example 4: Suppose a D number: $D=\{(3,0.2),(5,0.1),(6,0.1)\}$, then $I(D)=3 \times 0.2+$ $5 \times 0.1+6 \times 0.1=1.7$.

As we can see that, this $\mathrm{D}$ number is incomplete, since $0.2+0.1+0.1=0.4$ is less than 1 , which is not allowed in D-S theory.

\section{Methodology}

The flowchart of the proposed method for sustainability evaluation the transportation measure is shown in Figure 1, and the detailed steps of the proposed method are given as follows.

Step 1. Background introduction. The administrator should provide as more information as possible about the issue, involving implementation background, expected object, candidates, and so on. After that, the suitable evaluating proposals can be chosen according to the detailed information of the issue.

Step 2. Criteria and weights. The core of this step is to ascertain the detailed criteria which will be used to evaluate the performance of candidates. There are various ways to obtain applicable criteria for sustainability of transportation measures, such as experts' experiences, references of other cases, literature reviews and brainstorming. The criteria should be adopted according to the actual situation. When criteria are ascertained, the next is to allocate the weight to each criterion. There are many approaches to assign weights to criteria, such as AHP method.

Step 3. Data collection. When criteria and corresponding weights are obtained, the collection process of original data of candidates should be executed. To avoid the single source of data and make the fairly and objectively assessment of the candidates, the sources of data collection should be diversified. The collected original data may be presented in 
various types, but they should be transformed to the unified form of $\mathrm{D}$ numbers.

Step 4. Information integration. When the data collection process is completed and the data are all in the unified form of $\mathrm{D}$ numbers, the property of integration of $\mathrm{D}$ numbers will be carried out to perform the process of data fusion.

Step 5. State estimation. The transport sustainability index (TSI) (Reisi, Aye, Rajabifard, \& Ngo, 2014) will be computed based on the criteria and weights, and the data collected from multisources. It should be pointed out that, there will exist two stages of the city state, pre-test and post-test phases of the transportation measure. Pre-test is the TSI stage before implementing the transportation measure, and post-test indicates the statues of TSI stage after implemented the transportation measure.

Step 6. Impact assessment. Observe the data of pretest and post-test stages through the transportation measure. If the data of post-test stage is bigger than the pre-test stage, then the transportation measure is said

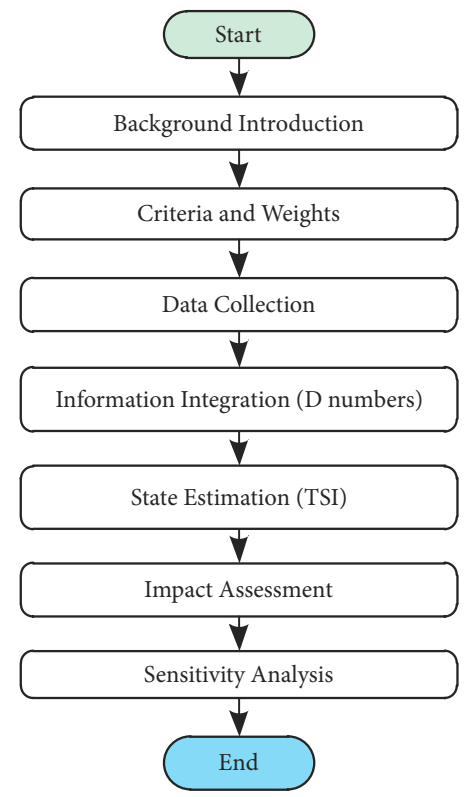

Figure 1. The flowchart of proposed method to be positive, and it should be recommended for adoption. Otherwise, the transportation measure is deemed to be negative, and it is not suitable for the city sustainablility.

Step 7. Sensitivity analysis. Sensitivity analysis (Saltelli, Chan, \& Scott, 2000) is used to address the question of "How sensitive is the overall decision to small changes in the individual weights assigned during the pair-wise comparison process?". It is an useful tool when uncertainties exist in the importance of different factors. Sensitivity analysis is involved to determine the influence of criteria weights in the decision making.

\section{Application}

Carsharing differs from traditional rental cars in many aspects, and there are several reasons for choosing carsharing. Carsharing can be available at anytime without the limitation of office hours. The reservation, pick up, and return of cars of carsharing are all self-service. Users of carsharing are members and have been pre-approved to drive authorized by a company or an organization. The principle of carsharing is simple, that is individuals gain the benefits of private cars without additional costs and responsibilities of ownership (Shaheen, Sperling, \& Wagner, 1999). Carsharing provides the potential to reduce the costs of vehicle travel for the individual as well as for society, that is the extra-costs of vehicle purchase, gas money, repair and maintenance fee, parking fee and insurance premium are all transferred from individual user to the company of carsharing (Awasthi, Chauhan, Hurteau, \& Breuil, 2008). Carsharing can also contribute to reduce congestion and pollution in the city. Carsharing is 
effective and attractive when it is regarded as a transportation mode that fills the gap between transit and private cars, and can be linked to other models and transportation services as a mobility package.

Carsharing is becoming increasingly popular with its promise of personal convenience and social improvement. Carsharing operates in thousands of cities worldwide, reported by World Carshare Consortium (2009), and it trends to locate in these densely populated areas, such as city centers and more recently university and other campuses. From Car2go blog (2018), Car2go is the largest carsharing company of Germany in the world with more than 3 million registered members, more than 14000 vehicles and more than 90 million running kilometers, until 2017. There exist two different types of carsharing services, as introduced by social network of alumniportal Deutschland (2015). One is named station-based service in which the vehicle is picked up and dropped off within a predetermined place. Another is called free-floating service which allows users to pick up and park cars in any public place within an established zone (Ampudia-Renuncio, Guirao, \& Molina, 2018). Thus, the service of free-floating provides a more flexible way for users than station-based. It should be pointed out the new energy technologies, such as electric, are suitable for these vehicles of stationbased, because for the convenience and availability of energy supplement at pre-assigned places (Cartenì, Cascetta, \& de Luca, 2016). The conventional fuel vehicles are qualified for both free-floating and station-based carsharing services.

In this section, an application of carsharing (Awasthi \& Chauhan, 2011) will be used to demonstrate the effectiveness of the proposed method. One city wants to improve the transport condition with the aid of carsharing. Before implementation of the transportation measure of carsharing, an assessment on city sustainability is used to determine whether it will bring positive effect or not. It should be pointed out that the information collected in this example has been amended for some confidentiality reasons. All information sources are supposed to be totally reliable and the criteria are independent of each other. The detailed steps of evaluation are given as follows.

Step 1. Criteria and weights. The nine criteria of costs (C1), fuel consumption (C2), air quality (C3), noise (C4), number of users (C5), spatial accessibility (C6), satisfaction (C7), security (C8), and congestion levels (C9) were chosen from the aspects of economy, energy, environment, transport, society for evaluation carsharing, and they were assigned to the same weights for simplicity.

Step 2. Data collection. To be as objective as possible, the way to obtain data should be diversified. In this paper, the data are gathered from the aspects of subjectivity and objectivity, such as expert, survey, model and sensor. Experts who are skilled in the domain of urban transportation planning are asked to given their opinions. Surveys are assigned to the local residents, and their responses are aggregated. Models are used to compute a given set of input data to generate a set of simulation value. The sensors are used to obtain the data based on some measurement techniques. It should be pointed out that the data can be obtained at two stages: pre-test stage and post-test stage. The information sources given their opinions of three levels (increase (I), no change (N) and decrease (D)) in the form of D numbers. The evaluations from the four information sources for pretest stage of carsharing are presented in Table 1. And the evaluations for post-test stage of carsharing are presented in Table 2. 
Table 1. Original data collection (pre-test stage)

\begin{tabular}{|l|c|c|c|c|c|c|c|c|c|c|c|c|}
\hline \multirow{2}{*}{ Evaluation Criteria } & \multicolumn{3}{|c|}{ Expert } & \multicolumn{4}{c|}{ Model } & \multicolumn{3}{c|}{ Survey } & \multicolumn{3}{c|}{ Sensor } \\
\cline { 2 - 14 } & $\mathrm{I}$ & $\mathrm{N}$ & $\mathrm{D}$ & $\mathrm{I}$ & $\mathrm{N}$ & $\mathrm{D}$ & $\mathrm{I}$ & $\mathrm{N}$ & $\mathrm{D}$ & $\mathrm{I}$ & $\mathrm{N}$ & $\mathrm{D}$ \\
\hline Costs (C1) & 0.25 & 0.5 & 0.25 & 0.6 & 0.2 & 0.2 & 0.5 & 0.3 & 0.2 & 0.5 & 0.35 & 0.15 \\
\hline Fuel consumption (C2) & 0.3 & 0.4 & 0.3 & 0.4 & 0.4 & 0.2 & 0.4 & 0.4 & 0.2 & 0.2 & 0.3 & 0.5 \\
\hline Air quality (C3) & 0.65 & 0.2 & 0.15 & 0.7 & 0.1 & 0.2 & 0.6 & 0.2 & 0.2 & 0.8 & 0.1 & 0.1 \\
\hline Noise (C4) & 0.25 & 0.1 & 0.65 & 0.8 & 0.1 & 0.1 & 0.5 & 0.3 & 0.2 & 0.1 & 0.1 & 0.8 \\
\hline Number of users (C5) & 0.7 & 0.1 & 0.2 & 0.2 & 0.7 & 0.1 & 0.8 & 0.1 & 0.1 & 0.6 & 0.3 & 0.1 \\
\hline Spatial accessibility (C6) & 0.5 & 0.2 & 0.3 & 0.6 & 0.3 & 0.1 & 0.5 & 0.3 & 0.2 & 0.7 & 0.2 & 0.1 \\
\hline Satisfaction (C7) & 0.6 & 0.3 & 0.1 & 0.7 & 0.2 & 0.1 & 0.6 & 0.3 & 0.1 & 0.8 & 0.1 & 0.1 \\
\hline Security (C8) & 0.4 & 0.3 & 0.3 & 0.4 & 0.4 & 0.2 & 0.4 & 0.4 & 0.2 & 0.5 & 0.2 & 0.3 \\
\hline Congestion levels (C9) & 0.4 & 0.2 & 0.4 & 0.1 & 0.4 & 0.5 & 0.2 & 0.3 & 0.5 & 0.2 & 0.2 & 0.6 \\
\hline
\end{tabular}

Notes: I: increase; N: no change; and D: decrease.

Table 2. Data collection (post-test stage)

\begin{tabular}{|l|c|c|c|c|c|c|c|c|c|c|c|c|}
\hline \multirow{2}{*}{ Evaluation Criteria } & \multicolumn{3}{|c|}{ Expert } & \multicolumn{3}{c|}{ Model } & \multicolumn{3}{c|}{ Survey } & \multicolumn{3}{c|}{ Sensor } \\
\cline { 2 - 13 } & $\mathrm{I}$ & $\mathrm{N}$ & $\mathrm{D}$ & $\mathrm{I}$ & $\mathrm{N}$ & $\mathrm{D}$ & $\mathrm{I}$ & $\mathrm{N}$ & $\mathrm{D}$ & $\mathrm{I}$ & $\mathrm{N}$ & $\mathrm{D}$ \\
\hline Costs (C1) & 0.3 & 0.5 & 0.2 & 0.4 & 0.4 & 0.2 & 0.2 & 0.7 & 0.1 & 0.1 & 0.6 & 0.3 \\
\hline Fuel consumption (C2) & 0.2 & 0.3 & 0.5 & 0.1 & 0.4 & 0.5 & 0.2 & 0.5 & 0.3 & 0.2 & 0.4 & 0.4 \\
\hline Air quality (C3) & 0.6 & 0.3 & 0.1 & 0.7 & 0.2 & 0.1 & 0.6 & 0.2 & 0.2 & 0.7 & 0.1 & 0.2 \\
\hline Noise (C4) & 0.1 & 0.3 & 0.6 & 0.1 & 0.1 & 0.8 & 0.2 & 0.1 & 0.7 & 0.2 & 0.2 & 0.6 \\
\hline Number of users (C5) & 0.8 & 0.1 & 0.1 & 0.7 & 0.2 & 0.1 & 0.6 & 0.1 & 0.3 & 0.8 & 0.1 & 0.1 \\
\hline Spatial accessibility (C6) & 0.6 & 0.3 & 0.1 & 0.8 & 0.1 & 0.1 & 0.6 & 0.1 & 0.3 & 0.7 & 0.2 & 0.1 \\
\hline Satisfaction (C7) & 0.7 & 0.2 & 0.1 & 0.8 & 0.1 & 0.1 & 0.6 & 0.2 & 0.2 & 0.6 & 0.3 & 0.1 \\
\hline Security (C8) & 0.25 & 0.35 & 0.4 & 0.3 & 0.4 & 0.3 & 0.2 & 0.5 & 0.3 & 0.2 & 0.4 & 0.4 \\
\hline Congestion levels (C9) & 0.2 & 0.3 & 0.5 & 0.1 & 0.2 & 0.7 & 0.2 & 0.2 & 0.6 & 0.2 & 0.4 & 0.4 \\
\hline
\end{tabular}

Notes: I: increase; N: no change; and D: decrease.

Step 3. Information integration. Taking evaluation criterion "costs (C1)" and information source of "expert" in Table 1 for example, "expert" believes that the probability of C1 will be increased as 0.25 , no change as 0.5 and decreased as 0.25 . That is " $\mathrm{I}=0.25, \mathrm{~N}=0.5, \mathrm{D}=$ 0.25 ". For the evaluation matrix in the discrete form of $\mathrm{D}$ numbers, they can be aggregated by the integration property of D numbers. Taking criteria C1 in Table 1 for example, the probability of "I" can be obtained by accumulation all the information sources' (expert, model, survey and sensor) opinion of " $\mathrm{I}$ ", that is " $0.25+0.6+0.5+0.5=1.85$ ". The probabilityof " $\mathrm{N}$ " is " $0.5+0.2+0.3+0.35=1.35$ ", and the probability of " $\mathrm{D}$ " is " $0.25+0.2+0.2+0.15=$ 0.8 ". Similarly, the other criteria of pre-test stage can also be obtained as shown in Table 3. And, the criteria of post-test stage of evaluation can also be aggregated, as shown in the last three rows of Table 3. 
Table 3. Data after information integration

\begin{tabular}{|l|c|c|c|c|c|c|}
\hline \multirow{2}{*}{ Evaluation Criteria } & \multicolumn{3}{|c|}{ Pre-test stage } & \multicolumn{3}{c|}{ Post-test stage } \\
\cline { 2 - 7 } & $\mathrm{I}$ & $\mathrm{N}$ & $\mathrm{D}$ & $\mathrm{I}$ & $\mathrm{N}$ & $\mathrm{D}$ \\
\hline Costs (C1) & 1.85 & 1.35 & 0.8 & 1.0 & 2.2 & 0.8 \\
\hline Fuel consumption (C2) & 1.3 & 1.5 & 1.2 & 0.7 & 1.6 & 1.7 \\
\hline Air quality (C3) & 2.75 & 0.6 & 0.65 & 2.6 & 0.8 & 0.6 \\
\hline Noise (C4) & 1.65 & 0.6 & 1.75 & 0.6 & 0.7 & 2.7 \\
\hline Number of users (C5) & 2.3 & 1.2 & 0.5 & 2.9 & 0.5 & 0.6 \\
\hline Spatial accessibility (C6) & 2.3 & 1.0 & 0.7 & 2.7 & 0.7 & 0.6 \\
\hline Satisfaction (C7) & 2.7 & 0.9 & 0.4 & 2.7 & 0.8 & 0.5 \\
\hline Security (C8) & 1.7 & 1.3 & 1.0 & 0.95 & 1.65 & 1.4 \\
\hline Congestion levels (C9) & 0.9 & 1.1 & 2.0 & 0.7 & 1.1 & 2.2 \\
\hline
\end{tabular}

Utility assessment (Johnson \& Huber, 1977) includes the entire process of identifying, measuring, and combining attributes to create an explicit value structure that can form a basis for evaluations and decisions. A set of utility for criteria is given by $u: u=\{(u(I), u(N), u(D)\}$ in this application, where $u(I)$ represents increased, $u(N)$ represents no change and $u(D)$ represents decreased. The set of utility is used for information integration of the stages of pretest and post-test. Since some criteria are the higher the higher utilities obtained and some are the higher the lower utilities obtained, there exist two values of utilities. For example, a higher "satisfaction (C7)" gets a higher utility value and a higher "fuels consumption (C2)" gets a lower utility value. In view of this, the utility values for the given nine criteria are calculated as shown in Table 4.

Table 4. Utility values for criteria

\begin{tabular}{|l|c|}
\hline \multicolumn{1}{|c|}{ Evaluation Criteria } & Utility values $\{u(I), u(N), u(D)\}$ \\
\hline $\begin{array}{l}\text { Costs (C1), Fuel consumption (C2), Noise (C4), } \\
\text { Congestion levels (C9). }\end{array}$ & $(0,0.3,1)$ \\
\hline $\begin{array}{l}\text { Air quality (C3), Number of users (C5), Spatial accessibility (C6), } \\
\text { Satisfaction (C7), Security (C8). }\end{array}$ & $(1,0.3,0)$ \\
\hline
\end{tabular}

It should be pointed out that the passive criteria of costs (C1), fuel consumption (C2), noise (C4) and congestion levels (C9) have higher values for low utilities, because they are the higher the worse. The remainder of positive criteria, such as air quality (C3), number of user (C5), spatial accessibility (C6), satisfaction (C7) and security (C8) get higher value for high utilities, since they are the higher the better. The global utility for criteria $i$ can be obtained as:

$$
u_{i}=\sum_{s=1}^{k} u_{i}\left(H_{k}\right) \times D_{i}\left(H_{k}\right) \text {, }
$$

where $H_{k}$ represents the evaluation level, $H_{k} \in\{I, N, D\}, u_{i}\left(H_{k}\right)$ represents the individual utility of an evaluation level $H_{k}$. $D_{i}\left(H_{k}\right)$ represents the values of $\mathrm{D}$ numbers to each evaluation level $H_{k}$, and $k$ represents the number of evaluation levels, in this paper, $k=3$. 
After D numbers to aggregate all the criteria, they global utilities as shown in Table 4, will be used for policymaker to express their opinions for evaluation criteria. Taking criteria "costs (C1)" of pre-test stage for example, combining its values of D numbers $(1.85,1.35,0.8)$ as shown in Table 3 and individual utility $(0,0.3,1)$ as shown in Table 4 , its global utility value can be obtained as follows:

$$
u_{1}=u_{1}(I) \times D_{1}(I)+u_{1}(N) \times D_{1}(N)+u_{1}(D) \times D_{1}(D)=0 \times 1.85+0.3 \times 1.35+1 \times 0.8=1.205 .
$$

Analogously, the other global utilities for criteria of pre-test stage and post-stage can also be obtained, as shown in Table 5 .

Table 5. Global utilities for criteria

\begin{tabular}{|l|c|c|}
\hline \multicolumn{1}{|c|}{ Evaluation Criteria } & Pre-test stage & Post-test stage \\
\hline Costs (C1) & 1.205 & 1.46 \\
\hline Fuel consumption (C2) & 1.65 & 2.18 \\
\hline Air quality (C3) & 2.93 & 2.84 \\
\hline Noise (C4) & 1.93 & 2.91 \\
\hline Number of users (C5) & 2.66 & 3.05 \\
\hline Spatial accessibility (C6) & 2.6 & 2.91 \\
\hline Satisfaction (C7) & 2.97 & 2.94 \\
\hline Security (C8) & 2.09 & 1.445 \\
\hline Congestion levels (C9) & 2.33 & 2.53 \\
\hline
\end{tabular}

Step 4. State estimation. The Transport Sustainability Index (TSI), based on the global utilities and weights of each criterion, can be used to express the state of city. Let TSI $\left(t_{\text {pre }}\right)$ and $T S I\left(t_{\text {post }}\right)$ denote the pre-test stage and post-test stage of the city, respectively. Suppose the nine criteria are assigned to the same weight with 0.111 , the values of $\operatorname{TSI}\left(t_{\text {pre }}\right)$ and $\operatorname{TSI}\left(t_{\text {post }}\right)$ can be obtained as follows.

$$
\begin{aligned}
& \operatorname{TSI}\left(t_{\text {pre }}\right)=1.205 \times 0.111+1.65 \times 0.111+2.93 \times 0.111+1.93 \times 0.111+2.66 \times 0.111+ \\
& 2.6 \times 0.111+2.97 \times 0.111+2.09 \times 0.111+2.33 \times 0.111=2.2601 ; \\
& T S I\left(t_{\text {post }}\right)=1.46 \times 0.111+2.18 \times 0.111+2.84 \times 0.111+2.91 \times 0.111+3.05 \times 0.111+ \\
& 2.91 \times 0.111+2.94 \times 0.111+1.445 \times 0.111+2.53 \times 0.111=2.4714 .
\end{aligned}
$$

Step 5. Impact assessment of the transport measure. We can see that $2.4714>2.2601$, that is the value of $\operatorname{TSI}\left(t_{\text {post }}\right)$ is bigger than $\operatorname{TSI}\left(t_{\text {pre }}\right)$. It means that the measure of carsharing will bring positive impact to the city and it should be recommended to the administrator for adoption.

Step 6. Sensitivity analysis. As mentioned above, for simplicity, the weights of criteria are assigned to the same. In order to assess the impact of carsharing more objective, an analysis of sensitivity is carried out to exam how the weights of criteria affect the results. Twenty-three experts are asked to allocate weights to the nine criteria independently, as shown in Table 6. The results of sensitivity analysis are presented in Figure 2. And we can see that eighteen 
experiments indicate that the values of $\operatorname{TSI}\left(t_{\text {post }}\right)$ is bigger than $\operatorname{TSI}\left(t_{\text {pre }}\right)$. That is under the most circumstances, the measure of carsharing brings positive impact to the city, which is useful for improving the sustainability of transport condition of the city.

Table 6. Sensitivity analysis through different weights

\begin{tabular}{|l|c|c|c|c|c|c|c|c|c|}
\hline \multirow{2}{*}{$\begin{array}{c}\text { Expert } \\
\text { No. }\end{array}$} & \multicolumn{9}{|c|}{ Criteria weights } \\
\cline { 2 - 10 } & C1 & C2 & C3 & C4 & C5 & C6 & C7 & C8 & C9 \\
\hline Exp.1 & 1 & 0 & 0 & 0 & 0 & 0 & 0 & 0 & 0 \\
\hline Exp.2 & 0 & 1 & 0 & 0 & 0 & 0 & 0 & 0 & 0 \\
\hline Exp.3 & 0 & 0 & 1 & 0 & 0 & 0 & 0 & 0 & 0 \\
\hline Exp.4 & 0 & 0 & 0 & 1 & 0 & 0 & 0 & 0 & 0 \\
\hline Exp.5 & 0 & 0 & 0 & 0 & 1 & 0 & 0 & 0 & 0 \\
\hline Exp.6 & 0 & 0 & 0 & 0 & 0 & 1 & 0 & 0 & 0 \\
\hline Exp.7 & 0 & 0 & 0 & 0 & 0 & 0 & 1 & 0 & 0 \\
\hline Exp.8 & 0 & 0 & 0 & 0 & 0 & 0 & 0 & 1 & 0 \\
\hline Exp.9 & 0 & 0 & 0 & 0 & 0 & 0 & 0 & 0 & 1 \\
\hline Exp.10 & 0 & 0 & 0.2 & 0 & 0.2 & 0.2 & 0.2 & 0.2 & 0 \\
\hline Exp.11 & 0.1 & 0.1 & 0.2 & 0.2 & 0.05 & 0.1 & 0.05 & 0.1 & 0.1 \\
\hline Exp.12 & 0.25 & 0.25 & 0 & 0.25 & 0 & 0 & 0 & 0 & 0.25 \\
\hline Exp.13 & 0.125 & 0.125 & 0.1 & 0.125 & 0.1 & 0.1 & 0.1 & 0.1 & 0.125 \\
\hline Exp.14 & 0.111 & 0.111 & 0.111 & 0.111 & 0.111 & 0.111 & 0.111 & 0.111 & 0.111 \\
\hline Exp.15 & 0.5 & 0.0625 & 0.0625 & 0.0625 & 0.0625 & 0.0625 & 0.0625 & 0.0625 & 0.0625 \\
\hline Exp.16 & 0.0625 & 0.5 & 0.0625 & 0.0625 & 0.0625 & 0.0625 & 0.0625 & 0.0625 & 0.0625 \\
\hline Exp.17 & 0.0625 & 0.0625 & 0.5 & 0.0625 & 0.0625 & 0.0625 & 0.0625 & 0.0625 & 0.0625 \\
\hline Exp.18 & 0.0625 & 0.0625 & 0.0625 & 0.5 & 0.0625 & 0.0625 & 0.0625 & 0.0625 & 0.0625 \\
\hline Exp.19 & 0.0625 & 0.0625 & 0.0625 & 0.0625 & 0.5 & 0.0625 & 0.0625 & 0.0625 & 0.0625 \\
\hline Exp.20 & 0.0625 & 0.0625 & 0.0625 & 0.0625 & 0.0625 & 0.5 & 0.0625 & 0.0625 & 0.0625 \\
\hline Exp.21 & 0.0625 & 0.0625 & 0.0625 & 0.0625 & 0.0625 & 0.0625 & 0.5 & 0.0625 & 0.0625 \\
\hline Exp.22 & 0.0625 & 0.0625 & 0.0625 & 0.0625 & 0.0625 & 0.0625 & 0.0625 & 0.5 & 0.0625 \\
\hline Exp.23 & 0.0625 & 0.0625 & 0.0625 & 0.0625 & 0.0625 & 0.0625 & 0.0625 & 0.0625 & 0.5 \\
\hline & & & & & & & & & \\
\hline
\end{tabular}

\section{Conclusions}

In this paper, a new method to evaluate the impact of transportation measure on city sustainability is proposed based on D numbers. The proposed method is composite of evaluation criteria selection, data collection, information fusion, evaluation of city sustainability by TSI, and impact assessment. Sensitivity analysis is also carried out to examine the influence of criteria weights in the process of decision making. A transportation measure of carsharing is used to demonstrate the effectiveness of the proposed method. 


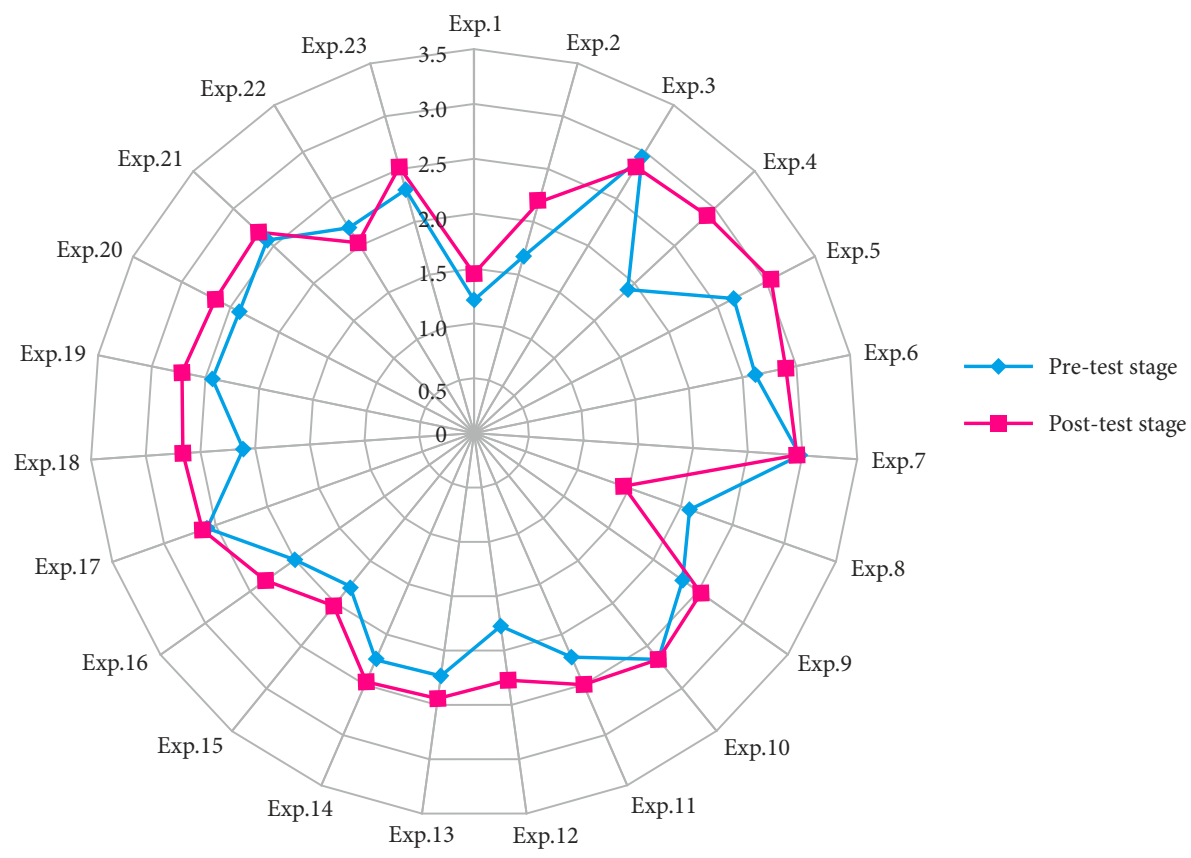

Figure 2. The results of sensitivity analysis

The new proposed method is qualified to deal with these heterogeneous, uncertain and incomplete information of different sources. The proposed method can deal with not only the complete information as mentioned in this manuscript of carsharing, but also these situations of incomplete information, since the inherent characteristic of D numbers. The proposed method is used to evaluate only one transport measure in this paper at a time. However, it can be also generalized to evaluate several transportation measures at a time, and to select the best one. And the proposed method is also suitable to other scenarios of decision making.

\section{Acknowledgements}

The authors greatly appreciate the reviews' suggestions and the editor's encouragement. This work was supported by National Natural Science Foundation of China (Grant Nos. 61573290, 61503237), and General Research Program of the Science Supported by Sichuan Minzu College (Grant No. XYZB18013ZB).

\section{References}

Akyelken, N., Banister, D., \& Givoni, M. (2018). The sustainability of shared mobility in London: The dilemma for governance. Sustainability, 10(2), 420. https://doi.org/10.3390/su10020420

Amegah, A. K., \& Agyei-Mensah, S. (2017). Urban air pollution in Sub-Saharan Africa: Time for action. Environmental Pollution, 220(Part A), 738-743. https://doi.org/10.1016/j.envpol.2016.09.042 
Ampudia-Renuncio, M., Guirao, B., \& Molina, R. (2018). The impact of free-floating carsharing on sustainable cities: analysis of first experiences in Madrid with the university campus. Sustainable Cities and Society, 43, 462-475. https://doi.org/10.1016/j.scs.2018.09.019

Anand, S., \& Sen, A. (2000). Human development and economic sustainability. World Development, 28(12), 2029-2049. https://doi.org/10.1016/S0305-750X(00)00071-1

Awasthi, A., \& Chauhan, S. S. (2011). Using AHP and Dempster-Shafer theory for evaluating sustainable transport solutions. Environmental Modelling \& Software, 26(6), 787-796. https://doi.org/10.1016/j.envsoft.2010.11.010

Awasthi, A., \& Chauhan, S. S. (2012). A hybrid approach integrating Affinity Diagram, AHP and fuzzy TOPSIS for sustainable city logistics planning. Applied Mathematical Modelling, 36(2), 573-584. https://doi.org/10.1016/j.apm.2011.07.033

Awasthi, A., Chauhan, S. S., Hurteau, X., \& Breuil, D. (2008). An analytical hierarchical process-based decision-making approach for selecting car-sharing stations in medium size agglomerations. International Journal of Information and Decision Sciences, 1(1), 66-97. https://doi.org/10.1504/IJIDS.2008.020049

Bachmann, F., Hanimann, A., Artho, J., \& Jonas, K. (2018). What drives people to carpool? Explaining carpooling intention from the perspectives of carpooling passengers and drivers. Transportation Research Part F: Traffic Psychology and Behaviour, 59(Part A), 260-268. https://doi.org/10.1016/j.trf.2018.08.022

Banister, D. (2008). The sustainable mobility paradigm. Transport Policy, 15(2), 73-80. https://doi.org/10.1016/j.tranpol.2007.10.005

Belenky, A. S. (2013). Operations research in transportation systems: Ideas and schemes of optimization methods for strategic planning and operations management (Vol. 20). Springer Science \& Business Media.

Bian, T., Zheng, H., Yin, L., \& Deng, Y. (2018). Failure mode and effects analysis based on D numbers and TOPSIS. Quality and Reliability Engineering International, 34(4), 501-515. https://doi.org/10.1002/qre.2268

Browne, D., O'Regan, B., \& Moles, R. (2008). Use of ecological footprinting to explore alternative transport policy scenarios in an Irish city-region. Transportation Research Part D: Transport and Environment, 13(5), 315-322. https://doi.org/10.1016/j.trd.2008.03.009

Burton, I. (1987). Report on reports: Our common future: The world commission on environment and development. Environment: Science and Policy for Sustainable Development, 29(5), 25-29. https://doi.org/10.1080/00139157.1987.9928891

Car2go blog. (2018). “We are 3 million!”. Retrieved from https://blog.car2go.com/2018/02/07/we-are3-million/

Carteni, A. (2017). A new look in designing sustainable city logistics road pricing schemes. WIT Transactions on Ecology and the Environment, 223, 171-181. https://doi.org/10.2495/SC170151

Carteni, A. (2018). A cost-benefit analysis based on the carbon footprint derived from plug-in hybrid electric buses for urban public transport services. Wseas Transactions on Environment and Development, 14, 125-135. Retrieved from http://hdl.handle.net/11591/390642

Cartenì, A., Cascetta, E., \& de Luca, S. (2016). A random utility model for park \& carsharing services and the pure preference for electric vehicles. Transport Policy, 48, 49-59.

https://doi.org/10.1016/j.tranpol.2016.02.012

Cartenì, A., De Guglielmo, M. L., \& Pascale, N. (2018). Congested urban areas with high interactions between vehicular and pedestrian flows: A cost-benefit analysis for a sustainable transport policy in Naples, Italy. The Open Transportation Journal, 12(1), 273-288.

https://doi.org/10.2174/1874447801812010273

Cartenì, A., De Guglielmo, M. L., Pascale, N., \& Calabrese, M. (2017). An adaptive rational decisionmaking process for developing sustainable urban mobility plans. International Journal of Civil Engineering and Technology, 8(7), 1147-1156. http://hdl.handle.net/11591/390647 
Cascetta, E. (2009). Transportation systems analysis: models and applications (Vol. 29). Springer Science \& Business Media. https://doi.org/10.1007/978-0-387-75857-2_2

Cascetta, E., \& Pagliara, F. (2013). Public engagement for planning and designing transportation systems. Procedia-Social and Behavioral Sciences, 87, 103-116. https://doi.org/10.1016/j.sbspro.2013.10.597

Cascetta, E., Carteni, A., \& Henke, I. (2017). Acceptance and equity in advanced path-related road pricing schemes. In 5th IEEE International Conference Models and Technologies for Intelligent Transportation Systems (MT-ITS) (pp. 492-496). IEEE. https://doi.org/10.1109/MTITS.2017.8005722

Cascetta, E., Carteni, A., Pagliara, F., \& Montanino, M. (2015). A new look at planning and designing transportation systems: A decision-making model based on cognitive rationality, stakeholder engagement and quantitative methods. Transport Policy, 38, 27-39.

https://doi.org/10.1016/j.tranpol.2014.11.005

Chen, L., \& Deng, X. (2018a). A modified method for evaluating sustainable transport solutions based on AHP and Dempster-Shafer evidence theory. Applied Sciences, 8(4), 563. https://doi.org/10.3390/app8040563

Chen, L., \& Deng, Y. (2018b). A new failure mode and effects analysis model using Dempster-Shafer evidence theory and grey relational projection method. Engineering Applications of Artificial Intelligence, 76, 13-20. https://doi.org/10.1016/j.engappai.2018.08.010

Cleary, J. (2009). Life cycle assessments of municipal solid waste management systems: A comparative analysis of selected peer-reviewed literature. Environment International, 35(8), 1256-1266. https://doi.org/10.1016/j.envint.2009.07.009

Cordera, R., dell'Olio, L., Ibeas, A., \& Ortúzar, J. D. D. (2018). Demand for environmentally friendly vehicles: A review and new evidence. International Journal of Sustainable Transportation, 13(3), 210-223. https://doi.org/10.1080/15568318.2018.1459969

Dempsey, N., Bramley, G., Power, S., \& Brown, C. (2011). The social dimension of sustainable development: Defining urban social sustainability. Sustainable Development, 19(5), 289-300. https://doi.org/10.1002/sd.417

Dempster, A. P. (2008). Upper and lower probabilities induced by a multivalued mapping. In Classic works of the Dempster-Shafer theory of belief functions (pp. 57-72). Springer, Berlin, Heidelberg. https://doi.org/10.1007/978-3-540-44792-4_3

Deng, X., \& Deng, Y. (2018). D-AHP method with different credibility of information. Soft Computing, 23(2), 683-691. https://doi.org/10.1007/s00500-017-2993-9

Deng, Y. (2012). D numbers: theory and applications. Journal of Information \& Computational Science, 9(9), 2421-2428.

Domarchi, C., Coeymans, J. E., \& de Dios Ortúzar, J. (2018). Shared taxis: modelling the choice of a paratransit mode in Santiago de Chile. Transportation, 1-26. https://doi.org/10.1007/s11116-018-9926-Z

Eliasson, J. (2009). A cost-benefit analysis of the Stockholm congestion charging system. Transportation Research Part A: Policy and Practice, 43(4), 468-480. https://doi.org/10.1016/j.tra.2008.11.014

Fan, G., Zhong, D., Yan, F., \& Yue, P. (2016). A hybrid fuzzy evaluation method for curtain grouting efficiency assessment based on an AHP method extended by D numbers. Expert Systems with Applications, 44, 289-303. https://doi.org/10.1016/j.eswa.2015.09.006

Fei, L., \& Deng, Y. (2018). A new divergence measure for basic probability assignment and its applications in extremely uncertain environments. International Journal of Intelligent Systems, 34(4), 584600. https://doi.org/10.1002/int.22066

Fei, L., Deng, Y., \& Hu, Y. (2018). DS-VIKOR: A new multi-criteria decision-making method for supplier selection. International Journal of Fuzzy Systems, 21(1), 157-175. https://doi.org/10.1007/s40815-018-0543-y

Guan, X., Liu, H., Yi, X., \& Zhao, J. (2018). The improved combination rule of D Numbers and its application in radiation source identification. Mathematical Problems in Engineering, 2018, ID 6025680. https://doi.org/10.1155/2018/6025680 
Han, Y., \& Deng, Y. (2018a). An enhanced fuzzy evidential DEMATEL method with its application to identify critical success factors. Soft Computing, 22(15), 5073-5090. https://doi.org/10.1007/s00500-018-3311-x

Han, Y., \& Deng, Y. (2018b). A hybrid intelligent model for assessment of critical success factors in high-risk emergency system. Journal of Ambient Intelligence and Humanized Computing, 9(6), 19331953. https://doi.org/10.1007/s12652-018-0882-4

Han, Y., \& Deng, Y. (2018c). An evidential fractal analytic hierarchy process target recognition method. Defence Science Journal, 68(4), 367-373. https://doi.org/10.14429/dsj.68.11737

Hashemkhani Zolfani, S., Maknoon, R., \& Zavadskas, E. K. (2016). An introduction to prospective multiple attribute decision making (PMADM). Technological and Economic Development of Economy, 22(2), 309-326. https://doi.org/10.3846/20294913.2016.1150363

Johnson, E. M., \& Huber, G. P. (1977). The technology utility assessment. IEEE Transactions on Systems, Man, and Cybernetics, 7(5), 311-325. https://doi.org/10.1109/TSMC.1977.4309719

Kaklauskas, A., Herrera-Viedma, E., Echenique, V., Zavadskas, E. K., Ubarte, I., Mostert, A., Podvezko, V., Binkyte, A., \& Podviezko, A. (2018). Multiple criteria analysis of environmental sustainability and quality of life in post-Soviet states. Ecological Indicators, 89, 781-807. https://doi.org/10.1016/j.ecolind.2017.12.070

Katzev, R. (2003). Car sharing: A new approach to urban transportation problems. Analyses of Social Issues and Public Policy, 3(1), 65-86. https://doi.org/10.1111/j.1530-2415.2003.00015.x

Keeney, R. L., Raiffa, H., \& Rajala, D. W. (1979). Decisions with multiple objectives: Preferences and value trade-offs. IEEE Transactions on Systems, Man, and Cybernetics, 9(7), 403-403. https://doi.org/10.1109/TSMC.1979.4310245

Keshavarz Ghorabaee, M., Zavadskas, E. K., Amiri, M., \& Turskis, Z. (2016). Extended EDAS method for fuzzy multi-criteria decision-making: an application to supplier selection. International Journal of Computers Communications \& Control, 11(3), 358-371. https://doi.org/10.15837/ijccc.2016.3.2557

Kunreuther, H., Grossi, P., Seeber, N., \& Smyth, A. (2003). A framework for evaluating the cost-effectiveness of mitigation measures. Columbia University, USA.

Larson, E. D. (2006). A review of life-cycle analysis studies on liquid biofuel systems for the transport sector. Energy for Sustainable Development, 10(2), 109-126.

https://doi.org/10.1016/S0973-0826(08)60536-0

Lazauskas, M., Zavadskas, E. K., \& Šaparauskas, J. (2015). Ranking of priorities among the Baltic capital cities for the development of sustainable construction. E\& M Ekonomie a Management, 18(2), 15-24. https://doi.org/10.15240/tul/001/2015-2-002

Li, M., Zhang, Q., \& Deng, Y. (2018). Evidential identification of influential nodes in network of networks. Chaos, Solitons \& Fractals, 117, 283-296. https://doi.org/10.1016/j.chaos.2018.04.033

Li, X., \& Chen, X. (2018). D-Intuitionistic hesitant fuzzy sets and their application in multiple attribute decision making. Cognitive Computation, 10(3), 496-505. https://doi.org/10.1007/s12559-018-9544-2

Li, Y., \& Deng, Y. (2018). Generalized ordered propositions fusion based on belief entropy. International Journal of Computers, Communications \& Control, 13(5), 792-807. https://doi.org/10.15837/ijccc.2018.5.3244

Lin, S., Li, C., Xu, F., Liu, D., \& Liu, J. (2018). Risk identification and analysis for new energy power system in China based on D numbers and decision-making trial and evaluation laboratory (DEMATEL). Journal of Cleaner Production, 180, 81-96. https://doi.org/10.1016/j.jclepro.2018.01.153

Litman, T., \& Burwell, D. (2006). Issues in sustainable transportation. International Journal of Global Environmental Issues, 6(4), 331-347. https://EconPapers.repec.org/RePEc:ids:ijgenv:v:6:y:2006:i:4 :p:331-347

Liu, H. C., You, J. X., Fan, X. J., \& Lin, Q. L. (2014). Failure mode and effects analysis using D numbers and grey relational projection method. Expert Systems with Applications, 41(10), 4670-4679.

https://doi.org/10.1016/j.eswa.2014.01.031 
Mo, H., \& Deng, Y. (2016). A new aggregating operator for linguistic information based on D numbers. International Journal of Uncertainty, Fuzziness and Knowledge-Based Systems, 24(06), 831-846. https://doi.org/10.1142/S0218488516500379

Mo, H., \& Deng, Y. (2018). A new MADA methodology based on D numbers. International Journal of Fuzzy Systems, 20(8), 2458-2469. https://doi.org/10.1007/s40815-018-0514-3

Moya-Gómez, B., \& García-Palomares, J. C. (2017). The impacts of congestion on automobile accessibility. What happens in large European cities?. Journal of Transport Geography, 62, 148-159. https://doi.org/10.1016/j.jtrangeo.2017.05.014

Naess, P. (2001). Urban planning and sustainable development. European Planning Studies, 9(4), 503524. https://doi.org/10.1080/713666490

Nordlund, A. M., \& Garvill, J. (2003). Effects of values, problem awareness, and personal norm on willingness to reduce personal car use. Journal of Environmental Psychology, 23(4), 339-347. https://doi.org/10.1016/S0272-4944(03)00037-9

Ogilvie, D., Egan, M., Hamilton, V., \& Petticrew, M. (2004). Promoting walking and cycling as an alternative to using cars: systematic review. BMJ, 329, 763. https://doi.org/10.1136/bmj.38216.714560.55

Opricovic, S., \& Tzeng, G. H. (2007). Extended VIKOR method in comparison with outranking methods. European Journal of Operational Research, 178(2), 514-529.

https://doi.org/10.1016/j.ejor.2006.01.020

Ortuzar, J., \& Willumsen, L. G. (2011). Modelling transport (4 ${ }^{\text {th }}$ ed.). John Wiley \& Sons.

Rai, H. B., van Lier, T., Meers, D., \& Macharis, C. (2017). Improving urban freight transport sustainability: Policy assessment framework and case study. Research in Transportation Economics, 64, 26-35. https://doi.org/10.1016/j.retrec.2017.08.005

Rehermann, F., \& Pablo-Romero, M. (2018). Economic growth and transport energy consumption in the Latin American and Caribbean countries. Energy Policy, 122, 518-527. https://doi.org/10.1016/j.enpol.2018.08.006

Reisi, M., Aye, L., Rajabifard, A., \& Ngo, T. (2014). Transport sustainability index: Melbourne case study. Ecological Indicators, 43, 288-296. https://doi.org/10.1016/j.ecolind.2014.03.004

Saltelli, A., Chan, K., \& Scott, E. M. (Eds.). (2000). Sensitivity analysis (Vol. 1). New York: Wiley.

Shafer, G. (1976). A mathematical theory of evidence (Vol. 42). Princeton University Press.

Shaheen, S. A., Sperling, D., \& Wagner, C. (1999). A short history of Carsharing in the 90's. The Journal of World Transport Policy \& Practice, 5, 18-40. Retrieved from https://escholarship.org/uc/ item/6p3305b0

Siksnelyte, I., Zavadskas, E. K., Bausys, R., \& Streimikiene, D. (2019). Implementation of EU energy policy priorities in the Baltic Sea Region countries: Sustainability assessment based on neutrosophic MULTIMOORA method. Energy Policy, 125, 90-102. https://doi.org/10.1016/j.enpol.2018.10.013

Siksnelyte, I., Zavadskas, E., Streimikiene, D., \& Sharma, D. (2018). An overview of multi-criteria decision-making methods in dealing with sustainable energy development issues. Energies, 11(10), 2754. https://doi.org/10.3390/en11102754

Singh, R. K., Murty, H. R., Gupta, S. K., \& Dikshit, A. K. (2009). An overview of sustainability assessment methodologies. Ecological Indicators, 9(2), 189-212. https://doi.org/10.1016/j.ecolind.2008.05.011

Singh, S., Olugu, E. U., Musa, S. N., Mahat, A. B., \& Wong, K. Y. (2016). Strategy selection for sustainable manufacturing with integrated AHP-VIKOR method under interval-valued fuzzy environment. The International Journal of Advanced Manufacturing Technology, 84(1-4), 547-563. https://doi.org/10.1007/s00170-015-7553-9

Smets, P., \& Kennes, R. (1994). The transferable belief model. Artificial Intelligence, 66(2), 191-234. https://doi.org/10.1016/0004-3702(94)90026-4

Social network of Alumniportal Deutschland. (2015). Mobile, flexible and eco-friendly the car sharing boom is not limited to Germany alone. Retrieved from https:/www.alumniportal-deutschland.org/ en/globalgoals/sdg-12-consumption/car-sharing/ 
Soria-Lara, J. A., \& Banister, D. (2018). Evaluating the impacts of transport backcasting scenarios with multi-criteria analysis. Transportation Research Part A: Policy and Practice, 110, 26-37. https://doi.org/10.1016/j.tra.2018.02.004

Steenberghen, T., \& Lopez, E. (2008). Overcoming barriers to the implementation of alternative fuels for road transport in Europe. Journal of Cleaner Production, 16(5), 577-590. https://doi.org/10.1016/j.jclepro.2006.12.001

Su, C. M., Horng, D. J., Tseng, M. L., Chiu, A. S., Wu, K. J., \& Chen, H. P. (2016). Improving sustainable supply chain management using a novel hierarchical grey-DEMATEL approach. Journal of Cleaner Production, 134(Part B), 469-481. https://doi.org/10.1016/j.jclepro.2015.05.080

Thill, J. C., Rogova, G., \& Yan, J. (2004). Evaluating benefits and costs of intelligent transportation systems elements from a planning perspective. Research in Transportation Economics, 8, 571-603. https://doi.org/10.1016/S0739-8859(04)08025-4

Toledo, T., \& Koutsopoulos, H. N. (2004). Statistical validation of traffic simulation models. Transportation Research Record, 1876(1), 142-150. https://doi.org/10.3141/1876-15

Venables, A. J. (2007). Evaluating urban transport improvements: cost-benefit analysis in the presence of agglomeration and income taxation. Journal of Transport Economics and Policy (JTEP), 41(2), 173-188.

Wei, G., Alsaadi, F. E., Hayat, T., \& Alsaedi, A. (2018). Bipolar fuzzy Hamacher aggregation operators in multiple attribute decision making. International Journal of Fuzzy Systems, 20(1), 1-12. https://doi.org/10.1007/s40815-017-0338-6

Wellar, B. (2009). Sampler of commentaries on methods and techniques that could be used in making decisions about identifying, Adopting or implementing sustainable transport practices. Canada: Wellar Consulting Inc.

Wellmann, T., Govindswamy, K., \& Tomazic, D. (2013). Integration of engine start/stop systems with emphasis on NVH and launch behavior. SAE International Journal of Engines, 6(2), 1368-1378. https://doi.org/10.4271/2013-01-1899

World Carshare Consortium. (2009). One Thousand World Carshare Cities in 2009. Retrieved from http://ecoplan.org/carshare/general/cities.htm

Xiao, F. (2018). A novel multi-criteria decision making method for assessing health-care waste treatment technologies based on D numbers. Engineering Applications of Artificial Intelligence, 71, 216225. https://doi.org/10.1016/j.engappai.2018.03.002

Yang, H., Deng, Y., \& Jones, J. (2018). Network division method based on cellular growth and Physarum-inspired network adaptation. International Journal of Unconventional Computing, 13(6), 477491. Retrieved from http://www.oldcitypublishing.com/pdf/8918

Yin, L., Deng, X., \& Deng, Y. (2019). The negation of a basic probability assignment. IEEE Transactions on Fuzzy Systems, 27(1), 135-143. https://doi.org/10.1109/TFUZZ.2018.2871756

Zavadskas, E. K., Antuchevičienè, J., \& Chatterjee, P. (2019). Multiple-Criteria Decision-Making (MCDM) techniques for business processes information management. Information, 10(1), 1-7. https://doi.org/10.3390/info10010004

Zavadskas, E. K., Kalibatas, D., \& Kalibatiene, D. (2016). A multi-attribute assessment using WASPAS for choosing an optimal indoor environment. Archives of Civil and Mechanical Engineering, 16(1), 76-85. https://doi.org/10.1016/j.acme.2015.10.002

Zhang, H., \& Deng, Y. (2018). Engine fault diagnosis based on sensor data fusion considering information quality and evidence theory. Advances in Mechanical Engineering, 10(11), 1687814018809184. https://doi.org/10.1177/1687814018809184 